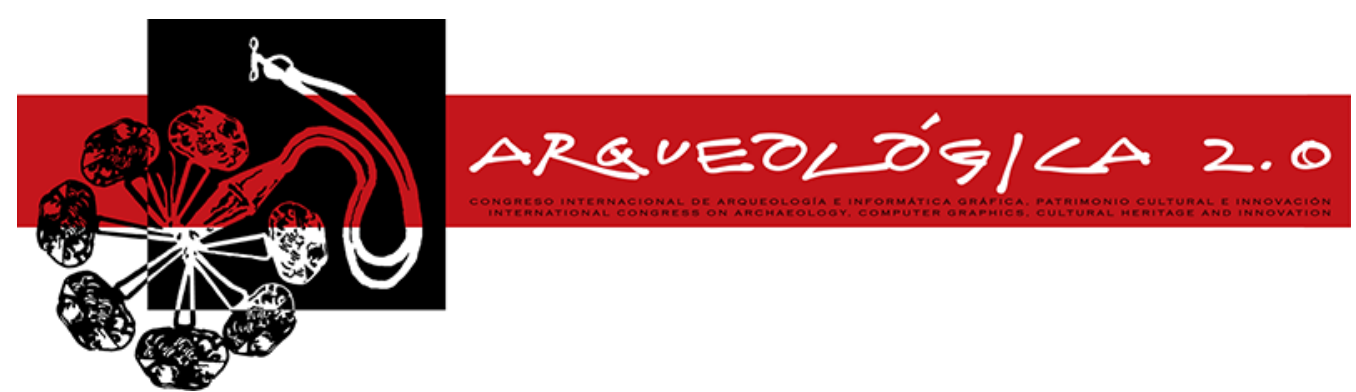

Proceedings of the $8^{\text {th }}$ International Congress

on Archaeology,

Computer Graphics,

Cultural Heritage and Innovation

'ARQUEOLÓGICA 2.0'

in Valencia (Spain),

Sept. $5-7,2016$

DOI: http://dx.doi.org/10.4995/arqueologica8.2016.3537

Received: 01/03/2016

Accepted: 10/04/2016

\title{
PROPUESTA DE REUBICACIÓN MEDIANTE RECONSTRUCCIÓN VIRTUAL. CASO DE ESTUDIO: RETABLO MAYOR DE SAN FRANCISCO DE SAN ESTEBAN DE GORMAZ (SORIA)
}

\author{
REUBICATION PROPOSAL THROUGH VIRTUAL RECONSTRUCTION. CASE STUDY: MAYOR ALTARPIECE OF \\ SAN FRANCISCO OF SAN ESTEBAN DE GORMAZ (SORIA)
}

\section{Mónica Sánchez}

Patrimonio Virtual, Universidad de Alicante, Campus de San Vicente, S/N, 03690 Alicante, España. msanchezy2015@gmail.com

\begin{abstract}
:
This paper briefly shows the skills acquired not only in the field of Conservation-Restoration, but also in Virtual Restoration as applied to Cultrual Heritage. The work under consideration is the Mayor Altarpiece of the old Convent of San Francsico, today Church of San Esteban Protomartir in San Esteban de Gormaz, Soria. Built in 1628 in one of the most important workshops of the Diocese, in 1985 renovation works and refurbishment of the church had uncovered wall paintings in advocation to the founder of the Order behind the wooden reredos, one of the few examples of pictorial altarpieces preserved in Spain that forced the transfer of the wooden altarpiece to a shrine in the same locality where it is currently disassembled.

This Cultural Property is a great example of heritage on which to apply the techniques of 3D modeling for virtual restoration and reconstruction of the environment as well, which aims to attempt visual recovery and potential unit without counyerfeiting, as methods of conservation, restoration and dissemination of Cultural Heritage.
\end{abstract}

Key words: conservation-Restoration, polychrome wood altarpiece, 3D modeling, virtualr restoration, virtual reconstruction, virtual architecture

\section{Resumen:}

En este artículo se muestran brevemente las competencias adquiridas no sólo en el ámbito de la ConservaciónRestauración, sino también en el de la Restauración Virtual aplicada al Patrimonio Cultural. La obra objeto de estudio es el Retablo Mayor del antiguo Convento de San Francisco, actual Iglesia Parroquial de San Esteban Protomártir de San Esteban de Gormaz, Soria. Construido en 1628 en uno de los talleres más importantes de la Diócesis, en 1985 unas obras de remodelación de la iglesia dejaron al descubierto unas pinturas murales en advocación al santo fundador de la Orden tras el conjunto de madera, uno de los escasos ejemplos de retablos pictóricos que se conservan en la España, que obligaron al traslado del retablo de madera a una ermita de la misma localidad donde se encuentra desmontado actualmente.

Este Bien Cultural es un gran ejemplo de Patrimonio sobre el que aplicar las nuevas tecnologías a través del modelado 3D realizando la restauración y reconstrucción virtuales tanto del entorno como de la obra, basadas en el intento de recuperación visual y de la unidad potencial sin llegar a la falsificación, a expensas de su posterior aplicación física valorando los múltiples factores que intervienen siendo, además, métodos de conservación, restauración y difusión de Patrimonio.

Palabras clave: conservación-Restauración, retablo madera policromada, modelado 3D, restauración virtual, reconstrucción virtual, arquitectura virtual

\section{Introducción}

El retablo de San Francisco es un gran ejemplo de patrimonio sobre el que aplicar las nuevas tecnologías como métodos de conservación, restauración y difusión a generaciones futuras.
La importancia de este conjunto viene dada, en primer lugar, por constituirse como una de las manifestaciones artísticas más importantes del patrimonio cultural, destacando de un modo más singular por sus dimensiones de escala monumental, así como por haberse construido en uno de los talleres oxomensessorianos más importantes del Renacimiento sacro (Fig. 
1). Datado en 1628 (Arranz 1985), responde a la tipología de retablo romanista sujeto en su arquitectura y decoración a un ritmo evolutivo correspondiente a la primera mitad del siglo XVII, una etapa más romanista que muestra la raíz del clasicismo, con la peculiaridad de instituirse como una de las escasas muestras que incorporan columnas mixtas, entorchadas y estriadas o la interposición de frontones curvos y partidos, matices que distinguen la línea estilística de la obra.

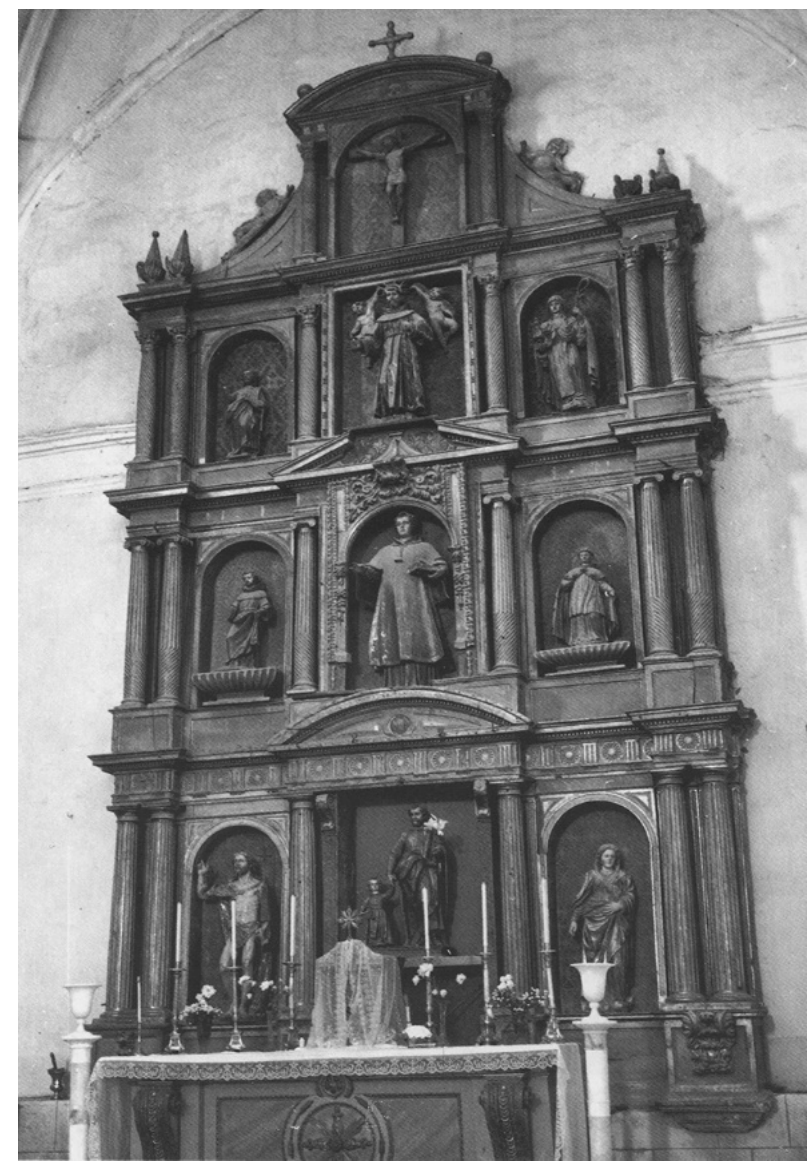

Figura 1: Imagen de "La escultura romanista en la Diócesis de Osma-Soria" de D. José Arranz Arranz (1986): retablo de San ubicación original.

La peculiaridad de esta estructura ornamental construida en "ad hoc" con indiferencia de un esquema iconográfico y escultórico- se debe a su historia material y cultural. Ubicado en el interior del antiguo Convento de San Francisco (Fig. 2), en la capilla de la actual iglesia parroquial de San Esteban Protomártir (Antón 2013), unas obras realizadas entre los años 1982 y 1985 dejaron al descubierto un retablo de pintura mural de mediados del siglo XVI oculto tras el de madera policromada, donde la conservación de las pinturas predominó, por su calidad y cronología, sobre el conjunto retablístico, el cual se llevó a la ermita de San Roque (Fig. 3), situada a escasos metros de la iglesia, donde permanece desmontado a día de hoy.

Es indudable que el proceso de deterioro de la obra ha evolucionado negativamente durante los últimos treinta años debido al sistema constructivo de baja calidad del inmueble (Carrasón 2008) en el que se ampara, así como por la agresión de la humedad, viéndose reflejado directamente en el retablo a través de indicadores patológicos (Fig. 4) que permiten analizar el precario estado de conservación que presenta.
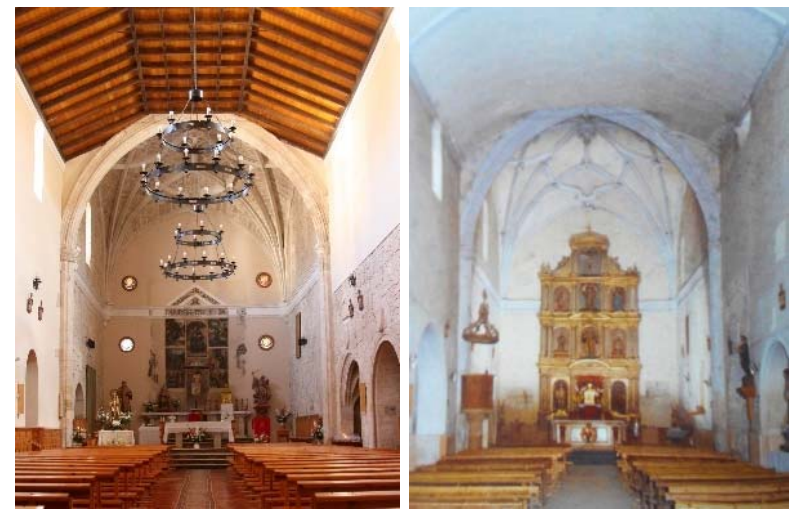

Figura 2: a) Imagen cedida por D. Fortunato Antón Nuño: retablo de San Francisco en ubicación original; b) pinturas murales de San Francisco restauradas.

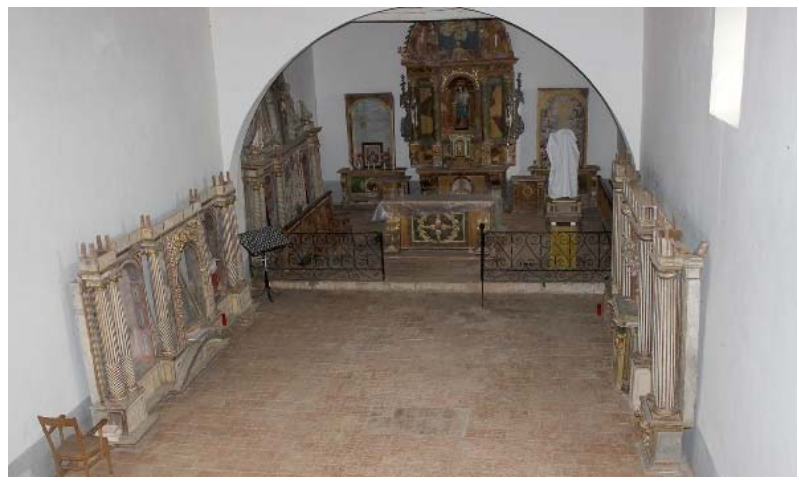

Figura 3: Disposición de los cuerpos del retablo de San Francisco en el interior de la ermita de San Roque.

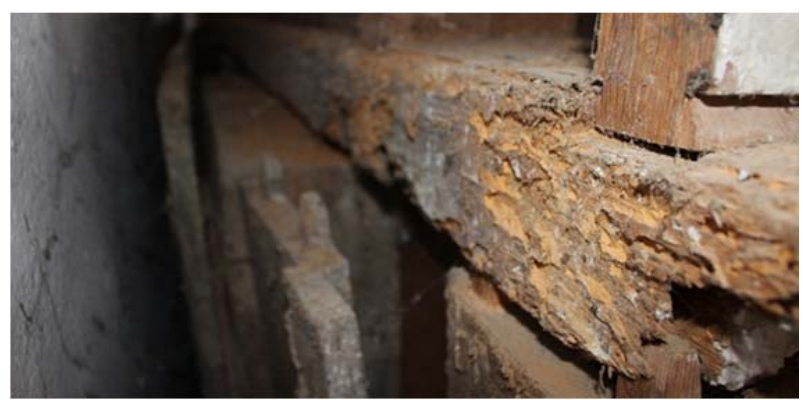

Figura 4: Detalle de alteraciones localizadas en el conjunto: ataque de xilófagos.

Atendiendo a la imposibilidad de una intervención próxima, es destacable la sinergia entre las disciplinas que abarcan las nuevas tecnologías y el patrimonio cultural, permitiendo utilizar distintas técnicas virtuales sobre piezas de estas características y mostrar la aplicación de las mismas a este tipo de obras.

\section{Documentación y modelado 3D}

\subsection{Preparación del material para la toma de imágenes}

La primera visita permitió analizar in situ las ventajas e inconvenientes que pudieran interferir positiva o negativamente en la fase de documentación. 
En cuanto a lo que se refiere al objeto a documentar, las dimensiones y disposición no hacían accesible el conjunto, especialmente a la trasera. Respecto al entorno, en el interior de la ermita se disponían numerosos obstáculos que entorpecerían el campo de visión. En lo que atañe a la iluminación, sólo se contaba con la luz natural que entraba por los ventanucos laterales, pues en el interior del inmueble no hay corriente eléctrica (Fig. 5).

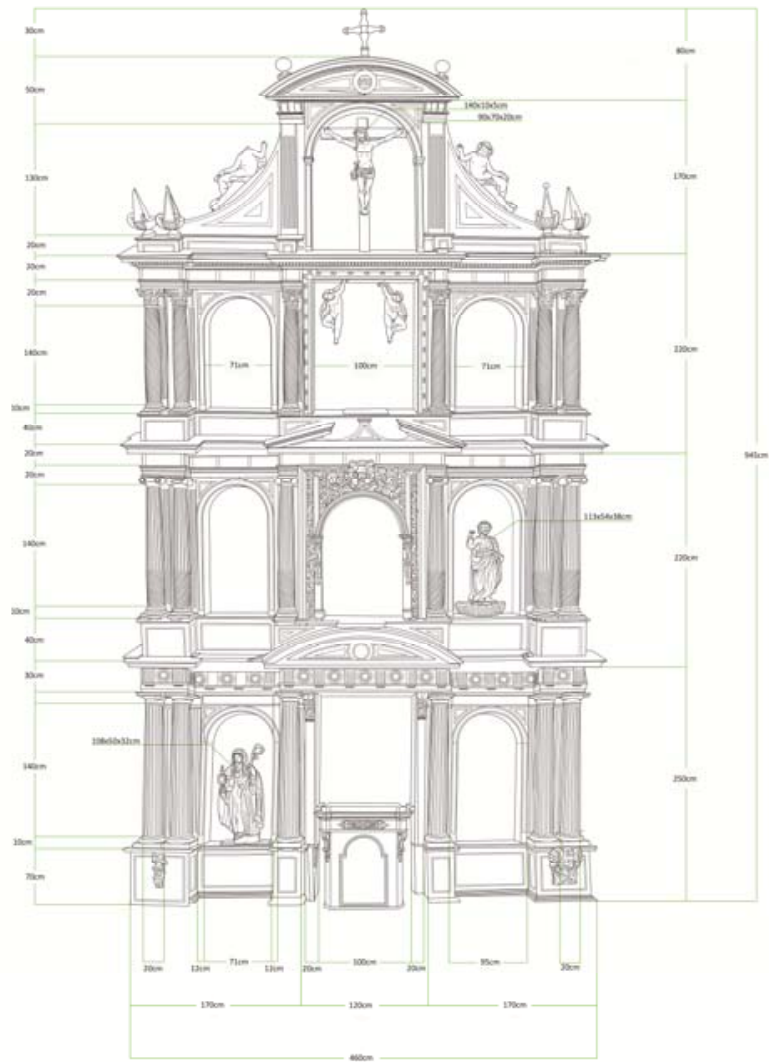

Figura 5: Habilitación del espacio de trabajo y muestra del equipo empleado.

El equipo de trabajo empleado estaba compuesto por:

- Dos cámaras digitales réflex: Canon EOS 450D y Canon EOS 600D.

- Dos trípodes: Manfrotto (1,80 metros), Velbon CX200 (1,50 metros).

- Dos focos LED: Creé.

\subsection{Toma de medidas}

Para poder respetar al máximo la integridad de la obra como de su contexto en la generación del modelo 3D, se procedió a la toma de medidas de la ermita y la iglesia mediante un metro láser preciso de 50 metros de alcance. Por su parte, las mediciones del retablo fueron las siguientes (Fig. 6):

\subsection{Construcción del modelo 3D}

El software utilizado es Blender, orientado al modelado de objetos y equipado con un conjunto de herramientas que permite trabajar en todas las fases que puede llegar a plantear un proyecto de infografía 3D.
En el modelo 3D únicamente se ha mostrado la arquitectura del retablo, excluyendo las esculturas debido a su distribución heterogénea e imposibilidad de documentación de todas ellas.

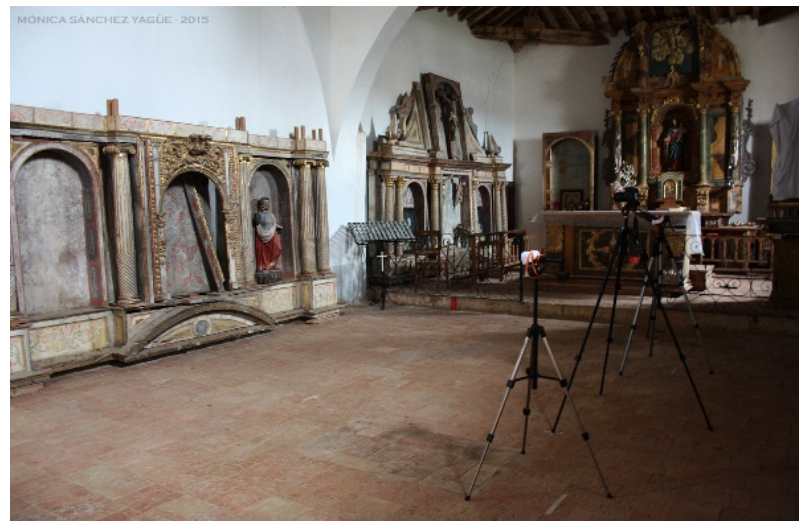

Figura 6: croquis de mediciones.

A partir de un rectángulo como estructura principal del retablo, se fue dividiendo en las diferentes partes que conforman las calles que lo conforman, junto con los entrantes y salientes o decoración correspondiente al entablamento (Fig. 7). Los cuerpos se fueron construyendo y colocando ordenadamente con el fin de reconstruir y restaurar virtualmente mediante la superposición y ensambles realizando el montaje del conjunto hasta finalizar el modelo $3 \mathrm{D}$ con el frontón curvo que remata el ático.

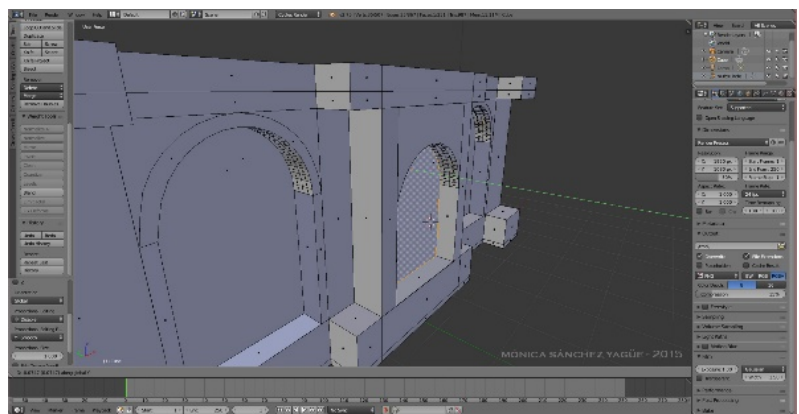

Figura 7: Captura de pantalla de Blender: creación de las hornacinas mediante la extrusión de caras.

Elementos como los remates piramidales situados en los laterales del tercer cuerpo se construyeron en su totalidad realizando la restauración al encontrarse pérdidas volumétricas, como sucede con las esferas que culminan los elementos piramidales (Fig. 8).

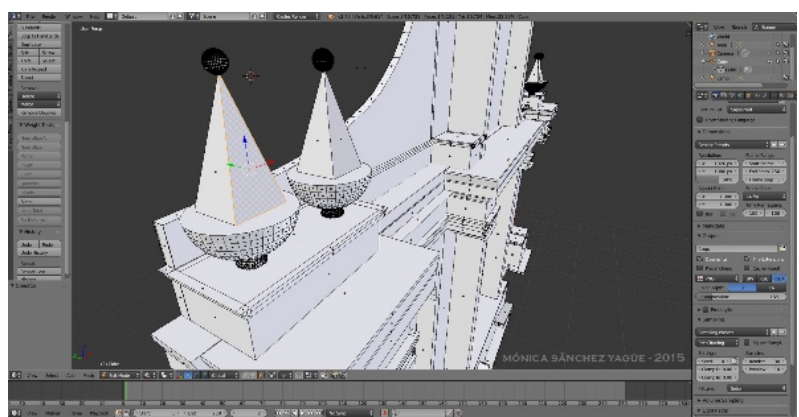

Figura 8: Captura de pantalla de Blender: reintegración volumétrica de elementos decorativos. 
Por último, elementos arquitectónicos y decorativos como columnas y capiteles se crearon tomando como referencia documentación gráfica para generar a partir de cilindros las distintas torsiones correspondientes a los cuatro órdenes clásicos presentes en los cuatro cuerpos del retablo (Fig. 9).

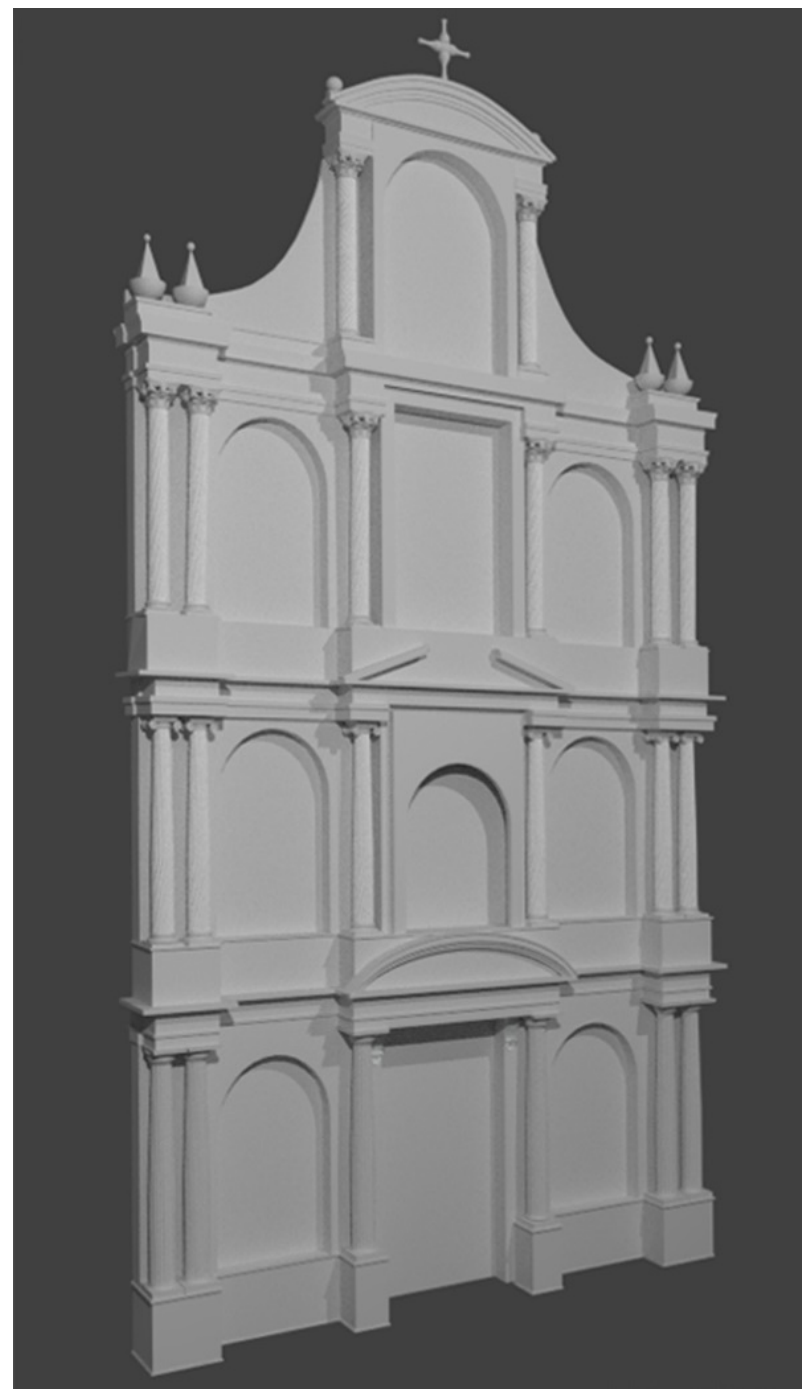

Figura 9: Maqueta 3D del montaje de los cuerpos del retablo.

Para la construcción de la iglesia (Fig. 10) se siguió la misma metodología de trabajo a través del modelado 3D.

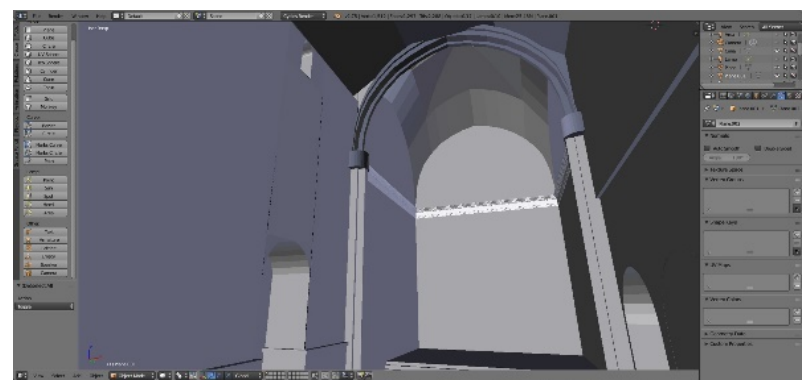

Figura 10: Captura de pantalla de Blender: construcción de las cubiertas de la iglesia.

\subsection{Aplicación de texturas}

Se constituye como una fase fundamental para dar realismo al modelo tridimensional mediante la aplicación de texturas procedentes de la fase de documentación fotográfica (Fig. 11).

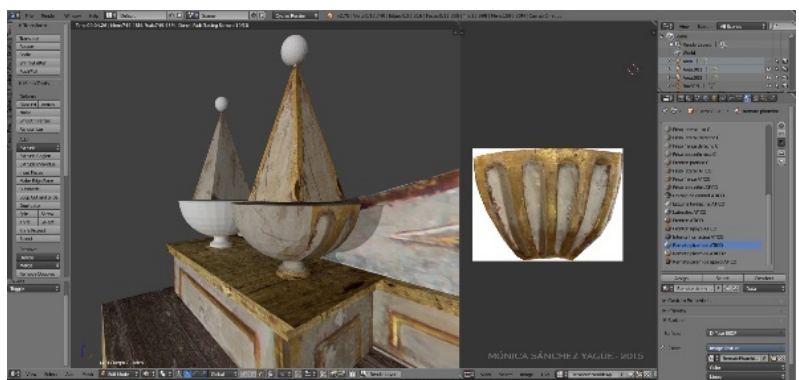

Figura 11: Captura de pantalla de Blender: aplicación de texturas en los distintos cuerpos y elementos del retablo.

El manejo de las texturas en numerosos casos requirió un procesado previo modificando con Photoshop los factores de niveles o curvas y brillo o contraste, adaptándolas posteriormente en Blender.

Por su parte, para contextualizar la iglesia y recrear su estado original incorporé texturas adicionales para crear visualmente el paso del tiempo sobre el inmueble.

\subsection{Obtención del modelo 3D: renderizado y animación 3D}

Los modelos finales se completaron mediante la inclusión de distintas fuentes de iluminación, obteniendo finalmente una serie de renderizados que permiten observar los modelos con detalle.

\subsubsection{Renderizado}

\subsubsection{Retablo montado}

Se puede observar la restauración virtual mediante el montaje y la reintegración de elementos perdidos (Figs. 12 y 13).

\subsubsection{Retablo en ubicación origina}

El segundo renderizado sirve como introducción y narración visual que complementa el estudio históricoartístico (Fig. 14). En este caso se muestra la localización original del retablo, atendiendo a su disposición física dentro de la iglesia parroquial, observando a su vez el margen de espacio del retablo respecto a la altura de la pared ya que no es el mismo que el de las paredes laterales de la posible nueva ubicación.

\subsubsection{Propuesta de reubicación I: No válida}

En el tercer renderizado se muestra la primera propuesta de reubicación con el fin de demostrar que no es posible por dos razones: en primer lugar, siguiendo la historia de este bien cultural, el no haberse montado de nuevo es debido a que prevaleció mantener visibles las pinturas murales que aparecieron tras él (Fig. 15). En segundo lugar, el espacio disponible entre la cabecera, el presbiterio y el altar es insuficiente para colocar el 
retablo paralelo a las pinturas manteniendo ambos una distancia mínima de 1,50 metros (Fig. 16).

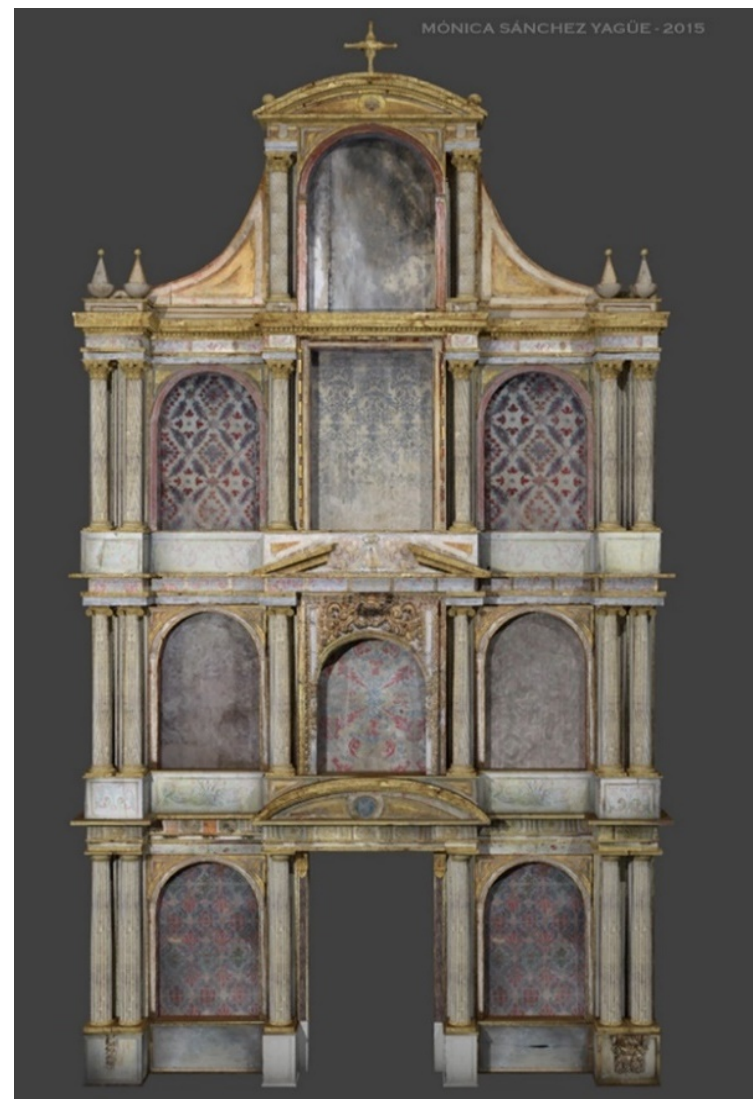

Figura 12: Renderizado del retablo montado. Vista frontal.

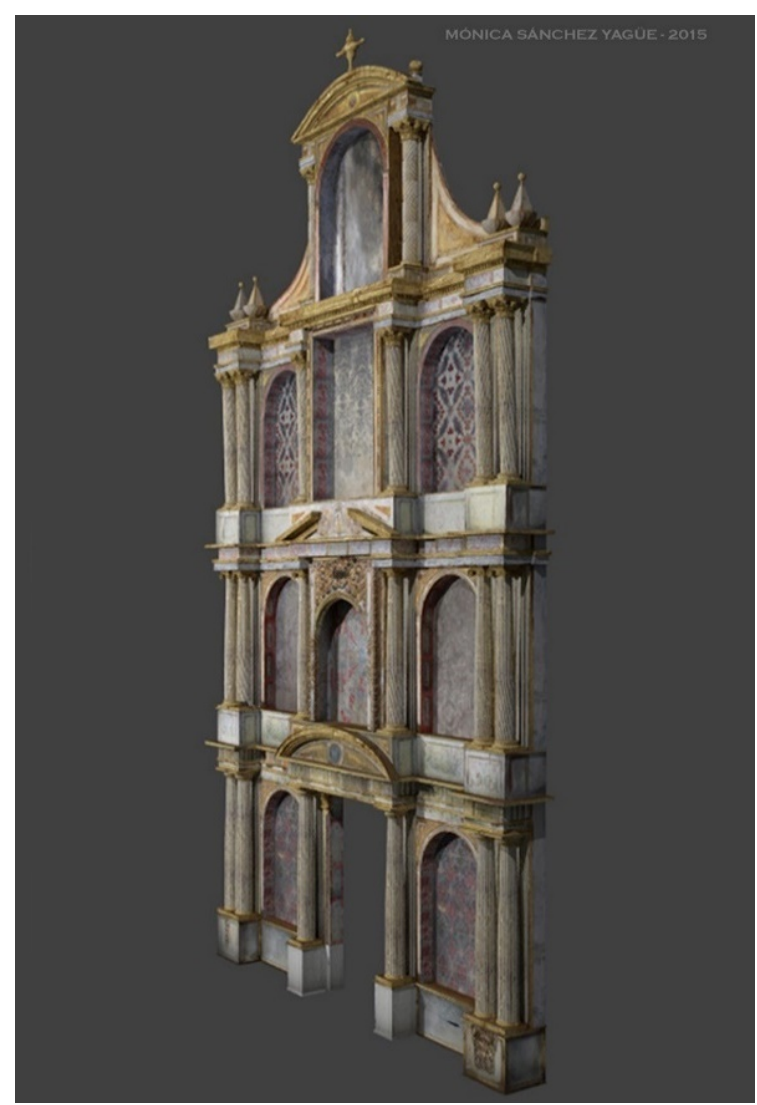

Figura 13: Renderizado del retablo montado. Vista lateral.

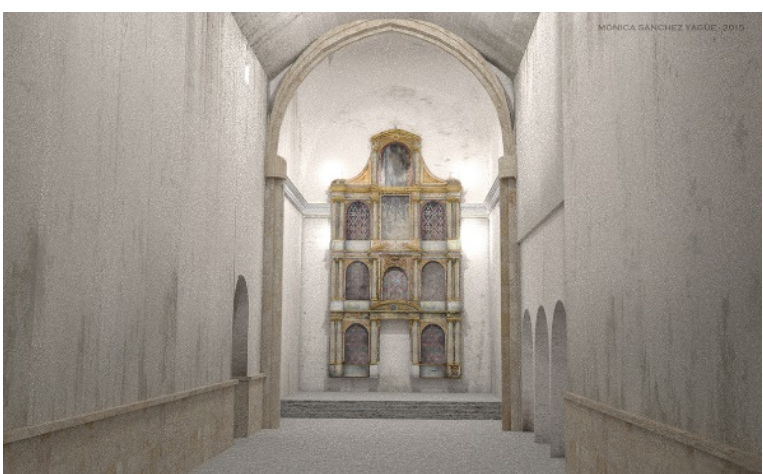

Figura 14: Renderizado del retablo en ubicación original.

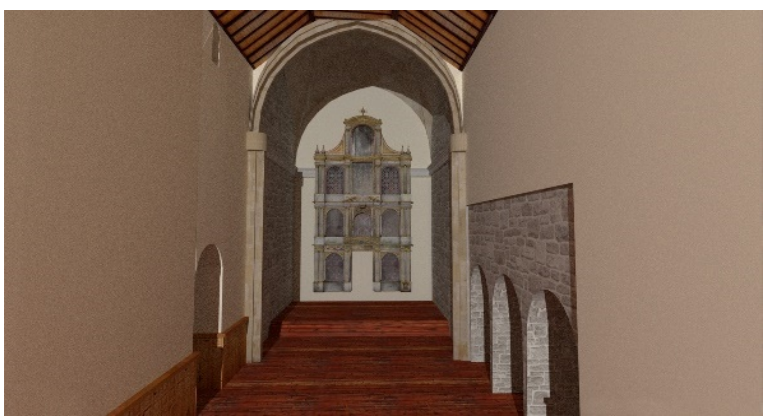

Figura 15: Renderizado I. Propuesta de reubicación I: No válida.

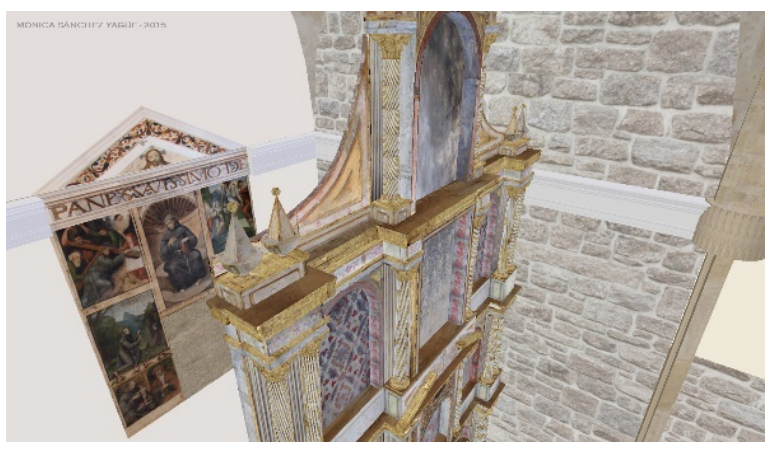

Figura 16: Detalle del retablo en paralelo a las pinturas murales.

\subsubsection{Propuestas de reubicación II y III: ¿Válidas?}

Como segunda y tercera propuesta de reubicación, se ha seguido la idea principal planteada por el Delegado de Patrimonio de la Diócesis de Osma-Soria y párroco de la localidad de San Esteban de Gormaz (Figs. 17 y 19).

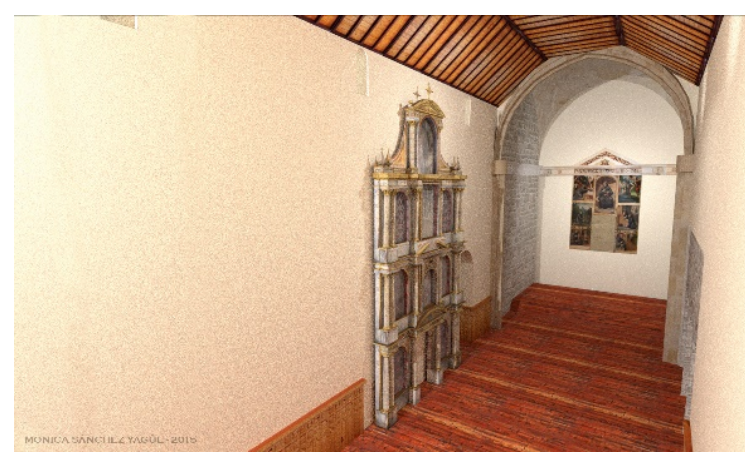

Figura 17: Renderizado II. Propuestas de reubicación II y III: ¿Válidas?. 


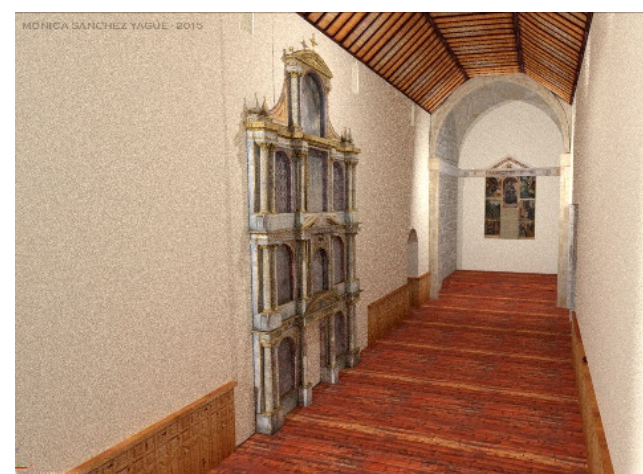

Figura 18: Renderizado III. Propuestas de reubicación II y III: ¿Válidas?.

Son opciones no descartadas pero el problema primordial reside en la altura disponible de la pared lateral, pues mide aproximadamente 9,7 metros mientras que el retablo alcanza los 9,4 metros, de manera que el espacio intermedio entre el retablo y la cubierta es muy reducido. Además, esto impediría la colocación de una bancada de piedra como se pretendía antes de la aparición de las pinturas murales en la cabecera.

En ambos casos debería incorporarse un panel explicativo con el fin de difundir la historia del bien cultural y la restauración para preservarlas en la historia.

\subsubsection{Animación 3D}

Como último paso, se ha propuesto la realización de una breve animación de aproximadamente 20 segundos de duración en Blender, cuyo fin es mostrar un recorrido virtual en el interior de la iglesia comenzando por el retablo de arriba abajo continuando hasta la cabecera donde poder apreciar las pinturas murales medievales, otorgando valor a las dos obras de arte (Figs. 19 y 20).

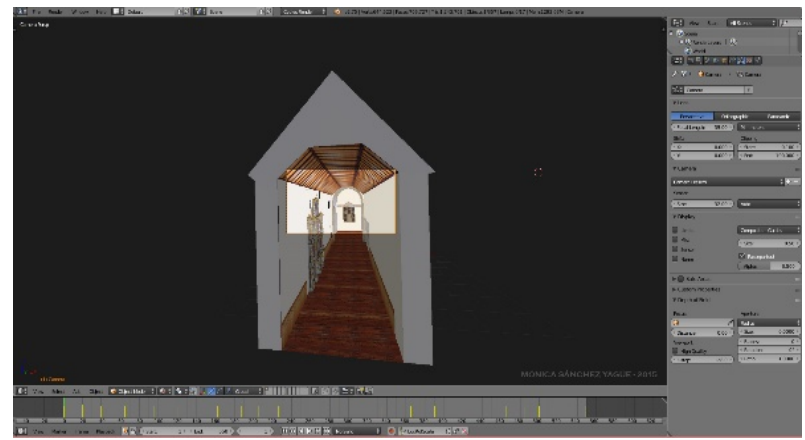

Figura 19: Posición de la cámara para comenzar la animación.

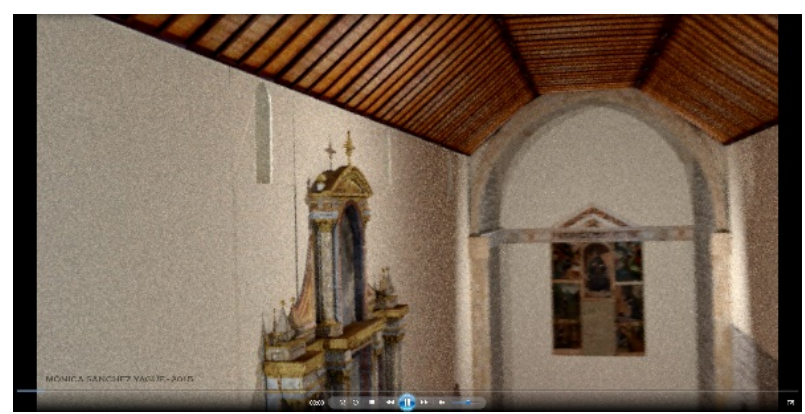

Figura 20: Visualización de la animación en el reproductor de video.

\section{Resultados}

Se optó por la elaboración de un modelo 3D con resultados lo más fieles posibles a la realidad, y la contextualización de la obra a través de la reconstrucción virtual del inmueble en el que se situaba en origen así como futura ubicación. Esta segunda fase ha permitido visualizar de una forma muy directa las distintas ubicaciones que se tienen en cuenta actualmente en el momento en el que se lleve a cabo la restauración, el traslado y montaje del retablo.

Con esto me refiero a que, una vez estudiadas las distintas propuestas de reubicación por los responsables de la Diócesis, fuimos conscientes de los inconvenientes reales que existen y que han de tenerse muy presentes en el momento de la reubicación, ya que actualmente se están tomando nuevas medidas de rehabilitación del inmueble para colocar el retablo de madera y, que de otra forma no habría sido posible averiguar.

De esta manera, se han desarrollado varias alternativas justificando cada una de las intervenciones.

Ante las posibles propuestas de reubicación, se ha seleccionado una de ellas sobre la que se ha realizado una animación 3D mostrando brevemente un recorrido desde la entrada de la iglesia hasta las pinturas murales que aparecieron tras el retablo de madera, simulando así cómo el espectador admiraría la obra en primera persona.

\section{Conclusiones}

Este retablo es un magnífico ejemplo de divulgación de patrimonio cultural sobre el que desarrollar la información apropiada para la puesta en valor de la obra, que va a mejorar la capacidad de transmisión y su accesibilidad. Se pretende, además, desarrollar el trabajo realizado de forma práctica, colocando un panel explicativo al lado del retablo con un fin didáctico, explicando y justificando la intervención.

Las nuevas tecnologías son las que tomen el papel más importante, como se ha demostrado previamente, para la difusión y desarrollo de los distintos aspectos de la restauración y la conservación preventiva. Es por ello que la reconstrucción y restauración virtuales desarrolladas anteriormente supondrán una parte fundamental de la conservación de la obra ya que virtualmente se podrá observar por parte del público tanto el paso de la historia como el trabajo del conservador-restaurador en la actualidad por las generaciones venideras.

En este artículo se recoge una de las partes que han conformado este proyecto. La labor de investigación ha permitido ir más allá en el ámbito de la ConservaciónRestauración, pudiendo así realizar un estudio en profundidad de la obra buscando las vías más adecuadas de actuación a través de distintas técnicas virtuales, obteniendo como resultado una infinidad de posibilidades para devolver la unidad potencial a las obras, observándose proyectos como los que se presentan en esta revista. 


\section{Referencias}

ANTÓN, F., 2013. El Románico de San Esteban de Gormaz. El año de la Fe. Soria, pp. 17-23.

ARRANZ, J., 1985. La escultura romanista en la Diócesis de Osma-Soria. Navarra, pp. 173-398.

ARRANZ, J., 1986. El Renacimiento sacro en la Diócesis de Osma-Soria. Navarra, pp. 256-262.

CARRASÓN, A., 2008. Algunas consideraciones sobre la conservación preventiva de retablos. Madrid: IPCE, 178 páginas. 